\title{
PEDAGOGIA UNIVERSITÁRIA EM CONSTRUÇÃO: DESAFIOS E APROXIMAÇÕES TEÓRICAS
}

http://dx.doi.org/10.5902/2318133830098

\author{
Neide Pena Cária \\ Rogério Abranches da Silva \\ Universidade do Vale do Sapucaí, Brasil.
}

\begin{abstract}
Resumo
Este texto é uma revisão de literatura sobre a temática pedagogia universitária. Tem-se como objetivo contribuir com as discussões em torno das questões que envolvem o ensino superior no que se referem ao ensino, à aprendizagem e à docência. Foi tomado como recorte temporal a década de 1990, caracterizada pela expansão e diversificação da oferta de ensino superior. Os aspectos teórico-conceituais tiveram como amparo os seguintes autores: Cunha (2004, 2006, 2016), Pimenta e Anastasiou (2005), Masetto (2006), Pimenta e Almeida (2011). Considerando que a universidade é uma instituição educativa, enraizada nos contextos sociais, econômicos e culturais e que tem como finalidade o permanente exercício da produção de conhecimento e da formação de profissionais, esta pesquisa se insere na perspectiva da formação profissional. Palavras-chave: pedagogia universitária; docência; ensinagem; formação profissional.
\end{abstract}

\section{UNIVERSITY PEDAGOGY UNDER CONSTRUCTION: CHALLENGING THEORETICAL APPROACHES}

\begin{abstract}
This paper is a literature review on the theme university pedagogy. It aims to contribute to the discussions around the issues involving higher education relating to teaching and learning. The decade of 1990 was taken as a timeframe, being characterized by the expansion and diversification of high education offer. The theoretical and conceptual aspects were supported by the following authors: Cunha (2004, 2006, 2016), Pimenta and Anastasiou (2005), Masetto (2006), Pimenta and Almeida (2011). Whereas the university is an educational institution, rooted in social, economic and cultural contexts and that aims the persistent production of knowledge and training of professionals, this research falls within the contexto of professional training.

Key-words: university pedagogy; teaching; learning; professional training.
\end{abstract}




\section{Introdução}

- ste artigo trata-se de uma revisão de literatura sobre a temática pedagogia universitária. Tem-se como objetivo contribuir com as discussões em torno das questões que envolvem a educação superior no que se referem ao ensino, à aprendizagem e à docência no ensino superior. Foi tomado como do em vista o recorte temporal a década de 1990, caracterizada pela expansão e diversificação da oferta de ensino superior.

Delineamos algumas características do cenário em que se inserem as instituições de ensino superior nas últimas décadas e a abordamos alguns aspectos teórico-conceituais dos seguintes autores: Maria Isabel Cunha, Selma Garrido Pimenta, Léa das Graças Anastasiou. Embasados na literatura utilizada neste trabalho, partimos do consenso de que um conjunto de fatores integrados compõe a denominada complexidade da educação, neste nível de ensino, como reconhecido por Cunha (2006) e outros pesquisadores do tema e, também, pelos demais pesquisadores que se dedicam ao estudo da educação superior, de modo geral.

Neste artigo procuramos fazer aproximações teóricas entre os desafios da educação superior e, também, a sua complexidade a esse novo paradigma de aula denominado ensinagem e aos fundamentos da pedagogia universitária. Tradicionalmente ensino e aprendizagem foram tratados como processos dicotômicos, sendo desconsiderado o processo dialético que ocorre entre esses fenômenos. Principalmente no ensino superior, como descrito por Pimenta e Anastasiou (2005), "muitos processos de ensino em curso na universidade não passam de meras reproduções de mini palestras ou reunião de um número determinado de pessoas ouvindo uma delas expor determinado assunto" (p. 204), em que $o$ ato de ensinar se resume ao momento da aula expositiva e encerrando-se nele.

No empenho de entender como acontecem as novas condições de ensino e aprendizagem, ou entre professores e alunos na produção de conhecimento e na formação, ou até mesmo identificar esforços de qualificação de novas práticas pedagógicas, assumimos com outros pesquisadores a complexidade que tomou conta da educação superior desde as últimas décadas do século 20, mostrando a necessidade de empreender e inovar no ensino superior, por meio de uma pedagogia própria ao ensino superior, a qual historicamente tem como função a preparação para uma profissão, mas só recentemente iniciaram as preocupações com relação ao ensino e à apresentação.

Nesse sentido, Pimenta e Anastasiou (2005) propõem uma superação do paradigma tradicional de ensino, cunhando um novo constructo denominado ensinagem, que supera a visão de senso comum da docência, tomando a aula "como momento e espaço privilegiado com relação encontro e de ações. Como tal, a aula "não deve ser 'dada' e nem 'assistida', mas 'construída, feita' pela ação conjunta de professores e alunos" ( $p$. 207).

\section{Desafios e complexidade no ensino superior}

Como analisam Pimenta e Anastasiou (2005), nas últimas três décadas ocorreu a expansão e a diversificação do ensino superior, visando à democratização da educação superior a fim de atender às tendências nacionais e internacionais de desenvolvimento. Segundo Cunha (2006), a complexidade do contexto do final do século 20 e o início do século 21 foi marcado pelas ideologias neoliberais e posições conservadoras. No 
entendimento da autora este cenário "induziu à reorientação dos sistemas educacionais, na perspectiva de fazer valer o mercado como eixo das definições políticas nesse campo" (p. 13). Procurou-se uma pedagogia que, sofrendo influências deste processo, vivesse metamorfoses no sentido de assumir sua condição de parceira dos processos produtivos, como primeiro compromisso educativo. Nesse contexto, suscitaram o aumento dos questionamentos em relação às práticas docentes e à sua formação, aliada à complexidade que envolve a universidade e demais instituições educativas de ensino superior. Sobre isso, afirmando enfaticamente que é preciso valorizar o ensino de graduação na universidade, Pimenta e Almeida (2011) argumentam que

\begin{abstract}
a universidade é uma instituição educativa cuja finalidade é o permanente exercício da crítica, que se sustenta na pesquisa, no ensino e na extensão. Ou seja, na produção do conhecimento a partir da problematização dos conhecimentos historicamente produzidos e de seus resultados na construção da sociedade humana e das novas demandas e desafios que esta coloca. Estes por sua vez, são produzidos e identificados inclusive nas análises que se realizam no próprio processo de ensinar, na experimentação e na análise dos projetos de extensão, por meio das relações que são estabelecidas entre os sujeitos e os objetos de conhecimento. (p. 21)
\end{abstract}

A complexidade da docência universitária também é reconhecida por Lucarelli (2007), por se configurar como um espaço de conexão de conhecimentos, subjetividades e culturas, que exige um conteúdo científico, tecnológico ou artístico especializado, orientado para a formação de uma profissão. Além disso, estudos realizados por Pimenta e Anastasiou (2005) evidenciam que muitos docentes, de universidades e outras instituições de ensino superior, são profissionais ou especialistas em seu ramo de conhecimento, mas não apresentam formação destinada ao magistério, ou seja, não se preparam para o processo de ensino: "Com isso, o exercício da docência tem por base muito mais a imitação da docência que tiveram, do que propriamente a incorporação do que de fato significa ser docente na educação superior" (Pimenta; Almeida, 2011, p. 80).

Reconhecer a estrutura do ensino superior, as diversas questões envolvidas na docência e as mudanças que ocorrem no cenário da educação superior nas últimas décadas são de suma importância e abre espaço para a proposição da chamada pedagogia universitária.

Visando aprofundar o argumento da complexidade da docência nesse nível de ensino diante do desafio da formação de profissionais, Lucarelli (2004) recorre a Tardif (2002) para evidenciar o que significa formação quando se trata de uma profissão.

A formação, no dizer de Tardif (2002), deve ser voltada para a reflexão, o discernimento e a compreensão de situações problemáticas do contexto da prática profissional e para a definição de objetivos pertinentes à situação e à identificação dos meios adequados para atingi-los. Isso implica, para o docente universitário, a tarefa de compreender criticamente a profissão em foco e o contexto mais amplo no qual ela se insere. Precisa, ainda, possibilitar, ao estudante, uma articulação consistente entre teoria e prática na formação de profissionais comprometidos com a transformação social, críticos, reflexivos e autônomos (Lucarelli, 2007). 
Segundo Tardif (2002), a formação para uma profissão tem se tornado uma tarefa cada vez mais desafiante para os docentes, na medida em que os profissionais estão cada vez mais submetidos a duas lógicas: uma burocrática e tecnocrática e outra do mercado. $O$ autor se refere ao processo de regulação realizado pelo Estado, à diversificação e especialização do mercado e à própria lógica do mercado no que se refere à mercantilização da educação, principalmente pelas instituições privadas. $\mathrm{Na}$ percepção de Lucarelli (2007), isso impacta fortemente o campo das profissões e, por consequência, das instituições que se ocupam da formação e educação superior, pois interfere nas políticas de gestão e nas práticas educativas dos docentes universitários, gerando impasses e distorções na relação pedagógica entre professores e estudantes, o que afeta diretamente da formação profissional.

Também Soares (2009) reconhece que essa conjuntura contribui para a redução da sua autonomia e, consequentemente, para a desprofissionalização, para a proletarização de alguns grupos profissionais e, ainda pode interferir na ética profissional quando a busca pelo lucro econômico ou poder passa a sobrepor-se à essência da educação e da formação humana. Explicitando ainda mais esta preocupação, Pimenta e Anastasiou (2011) discorrem ainda sobre o termo utilizado por alguns autores como um processo de fast-foodização da universidade (Boxus, Debry, Leclercq, 1998). No entendimento de Pimenta e Anastasiou (2011, p. 21) trata-se de "uma imensa usina de produção onde os estudantes são considerados apenas como elos do sistema no qual a aprendizagem é rápida e ligeira, exigindo apenas o suficiente para se obter créditos e diplomas".

Nessa mesma linha de crítica ao movimento de mercantilização da educação, Cunha (2016, p. 93) descreve que "tratamos com uma geração que adivinha insegurança no seu futuro profissional, que confia pouco nos conhecimentos que a educação superior Ihe aporta e precisa apostar na capacidade de continuar aprendendo".

Percebe-se que existe um questionamento coletivo e uma preocupação crescente que permeiam a questão da pedagogia universitária. Se, por um lado, existe uma tendência que desvirtua a relação pedagógica e educativa, por outro lado, este cenário pode ser enxergado como positivo no sentido de que esta inquietação traz cada vez mais os holofotes para o tema, uma vez que o conceito de pedagogia até então predominante no ensino superior origina-se da educação básica, com suas adaptações. Segundo Cunha (2006), é possível considerar que a educação superior tem, atualmente, no seu centro o professor universitário, desejoso de se tornar um profissional melhor, mais reconhecido e com maior vínculo com sua identidade docente.

A expressão pedagogia universitária é definida por Cunha (2004), na Enciclopédia de pedagogia universitária, como "um campo polissêmico de produção e aplicação dos conhecimentos pedagógicos na educação superior", que é reconhecido como um campo de "pedagogias múltiplas", uma vez que faz interlocução com distintos campos científicos dos quais "toma referentes epistemológicos e culturais para definir suas bases e características" (p 351).

Cabe destacar que a questão da educação superior tem despertado a atenção de uma grande quantidade de autores que vêm se debruçado em torno de discussões e pesquisas sobre o tema da docência, da formação de professores, da conexão teoria e prática, entre outros. Alguns autores, numa espécie de intenção de agrupar todas essas questões do ensino superior relacionadas ao ensino e à aprendizagem, cunharam o termo 
pedagogia universitária. Pelo exposto e, enquanto campo de produção e aplicação dos conhecimentos pedagógicos na educação superior, a pedagogia universitária se distingue da pedagogia em geral pelo seu interesse em compreender o processo de aprendizagem das pessoas adultas na sua trajetória de formação profissional.

Masetto (2006) e Soares e Cunha (2010) concordam que um dos desafios que concorrem para a complexidade da docência na educação superior diz respeito à especificidade do processo de aprendizagem de pessoas adultas na sua trajetória de formação profissional:

Diversos estudos, cujo pioneiro foi o de Knowles (1984 apud García, 1999), evidenciam que o processo de aprendizagem de adultos pressupõe o seu engajamento consciente e voluntário. Isso equivale a dizer que eles precisam compreender a finalidade de estudar os conteúdos apresentados, entender sua lógica e ter a possibilidade de negociar as formas propostas pelo professor para trabalhar esses conteúdos e para avaliar a aprendizagem realizada. (Soares; Cunha, 2010, p. 27)

Vale ainda frisar que a docência, como atividade que articula os processos de ensino e de aprendizagem, teve a sua complexidade reconhecida no século 17 por Comenius. Como relatado por Soares e Cunha (2010), em especial na sua obra Didática magna, o filósofo assim afirmava: "Ensinar é a arte das artes é, portanto, tarefa árdua que requer o juízo atento não de um só homem, mas de muitos, porque ninguém pode ser tão atilado que não Ihe escapem muitas coisas" (Comenius, 1997, p. 15 apud Soares; Cunha, 2010, p. 23).

As reflexões sobre a complexidade da docência universitária também são tratadas por Tardif (2002). Ele destaca o seu caráter interativo que se estabelece entre professor e aluno. Para o autor, ensinar é desenvolver um programa de interações com os estudantes, tendo em vista determinados objetivos formativos que envolvem a aprendizagem de conhecimentos, valores, atitudes, formas de ser e de se relacionar, entre outros. Nessa relação pressupõe um processo complexo de comunicação e negociação de expectativas, interesses, necessidades entre os atores envolvidos.

Cunha (2010), em suas diversas obras sobre o tema em análise, reconhece essa complexidade da docência no ensino superior que se explica pelo fato de seu exercício estar voltado para garantia da aprendizagem do estudante, deste nível de ensino, e não para a mera transmissão de conteúdos, o que significa considerar as especificidades que aí estão implicadas e, por isso mesmo, envolve condições singulares e exige uma multiplicidade de saberes, competências e atitudes que precisam ser apropriados e compreendidos em suas relações.

Não são poucos os estudos mais recentes que assumem a complexidade da docência universitária como um pressuposto, podendo ser considerada, atualmente, como um consenso entre os pesquisadores da área.

\section{A pedagogia universitária no âmbito das teorizações}

Apresentamos alguns fundamentos teóricos e conceituais sobre a chamada pedagogia universitária na sua relação com o contexto e histórico da educação superior no Brasil. Para isso, recorremos a alguns teóricos que há alguns anos vêm dedicando esforços, realizando pesquisas e provocando discussões sobre o ensino superior e, da 
mesma forma, fazendo proposições no sentido chamar a atenção para as questões pedagógicas neste nível de ensino. Entre eles destacamos: Maria Isabel Cunha, Selma Garrido Pimenta, Léa das Graças Anastasiou, Denise Leite, Marcos Tarciso Masetto, Elisa Lucarelli.

A pedagogia universitária é um tema relativamente novo nas pesquisas, pois até a bem pouco tempo a docência universitária não provocava discussões e questionamentos, sendo a sua prática mais comum caracterizada como tradicional. Como estabelecido na LDB de 1996, para lecionar no ensino fundamental e o médio é exigido formação superior em Pedagogia ou licenciatura. No entanto, para lecionar no curso superior, basta ter graduação em qualquer especialidade.

Conforme Leite (2005), pedagogia universitária surge na tradição cultural francesa centrada no estudo do conhecimento como matéria-prima do ensinar e aprender. No contexto latino-americano a pedagogia universitária, nucleada no campo educativo, opera no espaço transdisciplinar da academia. Tem como objeto de estudo o ensino, a aprendizagem e a avaliação na universidade. Preocupa-se com a formação docente para o exercício pedagógico profissional.

Para a autora, no contexto brasileiro, a pedagogia universitária vem sendo desafiada por diversos fatores, entre eles destacam-se a diversidade institucional, a ausência de programas continuados de formação docente e as constantes pressões sobre os currículos das carreiras profissionais, trazidas pelos processos avaliativos. No seu entendimento, "critica-se e escreve-se muito sobre ensino superior, mas produz-se pouco conhecimento sobre a pedagogia que o sustenta" (Leite, 2005, p. 57).

Nas últimas décadas, num contexto de regulação e avaliação, o MEC tem exigido que as instituições de ensino superior tenham uma parcela de profissionais com mestrado ou doutorado, mas ainda não oferecem preparação específica para o magistério superior. Desse ponto de vista, ainda predomina a ideia de que todo professor, automaticamente, é aquele que ensina, isto é, dispõe o conhecimento aos alunos (Cunha, 2004; Pimenta; Anastasiou, 2005).

Cunha (2004) descreve a expressão pedagogia universitária como sendo "um campo polissêmico de produção e aplicação dos conhecimentos pedagógicos na educação superior que envolve distintos campos científicos dos quais torna referentes epistemológicos e culturais para definir suas bases e características" (p. 321). Dessa forma, também é necessário reconhecer a especificidade que envolve a pedagogia universitária e a docência do ensino superior, diante dos conceitos apresentados pelas referidas autoras para que, então, inicie à compreensão da necessidade e relevância de tratar deste tema em particular.

\section{Retomando história: a pedagogia em questão}

Retomando a história da educação, Pimenta e Anastasiou (2005) analisam que o campo do didático se resumiria ao desenvolvimento de novas técnicas de ensinar, e o ensino à aplicação delas nas diversas situações. Enquanto adjetivo, o termo didática/didático é conhecido desde a Grécia, significando uma ação de ensinar presente nas relações entre os mais velhos e os jovens, crianças e adultos, na família e nos demais espaços sociais públicos (Pimenta; Anastasiou, 2005). Para autoras, a didática implícita na ação de ensinar de Sócrates, por exemplo, começará a ganhar contornos de

\begin{tabular}{l|l|l|l|l|l|l} 
Regae: Rev. Gest. Aval. Educ. & Santa Maria & v. 7 & n. 15 & Maio/ago. 2018 & p. 25-38
\end{tabular} 
campo específico e autônomo a partir de século 17, com o monge luterano João Amós Comênio (1562-1670), que escreve entre 1927 e 1657, a obra Didática magna: tratado da arte universal de ensinar tudo a todos. Entretanto, ao longo da história foi dada uma importância exacerbada às técnicas de ensino ou para ensinar, passando a resumir a Didática em meios e instrumentos eficientes para o desenvolvimento e o controle do processo de ensinar:

Nessa perspectiva de processo-produto, não cabe à Didática questionar os fins do ensino, uma vez que já estão previamente definidos pela expectativa que a sociedade (dominante) tem pela escola: preparar para 0 mercado de trabalho. Esse passa a ser o critério de avaliação do sistema escolar. (Pimenta; Anastasiou, 2009, p. 46)

Em Comenius encontram-se as bases para a generalização da escola a toda a população, requisito e demanda do desenvolvimento comercial, da constituição das cidades e, bem mais adiante, do capitalismo industrial, ao final do século 19. Já no século 18 Jean Jacques Rousseau foi o autor da segunda revolução didática. Sua obra deu origem a um novo conceito de infância, pondo em relevo sua natureza e transformando o método de ensinar em um procedimento natural, exercido sem pressa e sem livros. Somente no século 19 Johann Friedrich Herbart (1776-1841) erigiu as bases do que denominou pedagogia científica, salientando, com base na psicologia o que designou como passos formais da aprendizagem, dos quais decorrem os passos formais do ensino: clareza na exposição, associação dos conhecimentos novos com os anteriores, sistema e método. Essa didática herbartiana acentua a importância do professor no processo de ensino, pondo no preparo de sua aula, conforme os passos formais, a responsabilidade pelo sucesso do ensino (Pimenta; Anastasiou, 200).

Nos anos 1960 e, logo depois, no final do século 20, com o desenvolvimento tecnológico e a informática que acentuam a proeminência das técnicas e das tecnologias virtuais, emergiu a necessidade de compreender o funcionamento do ensino como fenômeno complexo, o que pode ser considerado como uma terceira revolução da Didática. Suas implicações estruturais e suas funções sociais repercutem em todos os níveis de ensino, inclusive na docência em instituições de ensino superior (Pimenta; Anastasiou, 2005).

Tomando a prática docente como atividade social, as referidas autoras destacam a necessidade e a importância de mais pesquisas e estudos que possam na área da docência do ensino superior, inclusive lançar mão de conhecimentos de outras áreas. 0 ensinar, enquanto atividade social tem como compromisso assegurar que todos aprendam, sendo neste sentido que a aprendizagem ao longo do processo de escolarização contribui para a humanização e, portanto, para a redução das desigualdades sociais. As autoras empreendem também uma crítica a esse modelo de aula no ensino superior, fazem um aprofundamento da discussão em torno do ato de ensinar realizado pelo professor e a aprendizagem do aprendiz, recorrendo a um rico aporte teórico. No contraponto desses argumentos, elas apresentam a sua crítica à situação tradicional do ensino superior e propõe um novo modelo de pedagogia para o ensino superior: 
Muitos processos de ensino em curso na universidade não passam de meras reproduções de mini palestras ou reunião de um número determinado de pessoas ouvindo uma delas expor determinado assunto. Muitas críticas já se encontram registradas sobre este aspecto, chegando a nomear aula magistral "local onde todos dormem e uma pessoa fala". Aí, de fato, o termo "ensinar" está sendo utilizado com a desconsideração de seus elementos essenciais. Neste contexto, 0 ato de ensinar resume-se ao momento da aula expositiva, encerrando-se nele e desconsiderando que da ação de ensinar, se conduzida de acordo com os fins educacionais, decorreria a ação de aprender (Pimenta; Anastasiou, 2005, p. 203)

É com esse entendimento que as autoras propõem o conceito de ensinagem, já o considerando um desafio a ser enfrentado pelos docentes universitários. Elas "propõem a ação docente [...] e a metodologia dialética como possibilidade de alteração do atual quadro relacional entre aluno, professor e conhecimento", evidenciando novos sentidos para o termo "estratégias" quando utilizado em sala de aula (Pimenta; Anastasiou, 2005, p. 28). O conceito de ensinagem é articulado ao termo estratégias de ensino referindo-se aos meios utilizados pelos docentes na articulação do processo de ensino e aprendizagem, de acordo com cada atividade e os resultados esperados. Nessa interpretação, as estratégias visam à consecução de objetivos que o docente estabelece e as habilidades a serem desenvolvidas em cada série de conteúdo.

Essas estratégias devem ser implementados a partir de situação de estudo, ou seja, uma situação real - complexa, dinâmica, plural - e conceitualmente rica, identificada nos contextos de vivência cotidiana dos alunos fora da escola, sobre a qual eles têm o que dizer e sejam capazes de produzir novos saberes, a partir da expressão de significados para tais saberes bem como defendendo seus pontos de vista.

Dessa forma, a situação de estudo é uma situação intencionalmente planejada, que visa a romper com a apresentação linear dos conteúdos científicos, desenvolvendo compreensões interdisciplinares, o que evidencia a necessidade de compreender 0 funcionamento do ensino como fenômeno complexo, suas implicações estruturais e suas funções sociais no caso da docência em instituições de ensino superior (Pimenta; Anastasiou, 2005). Essa forma de compreensão, tendo no centro o conceito de ensinagem, exige mais pesquisas e estudos que possam, inclusive, lançar mão de conhecimentos de outras áreas.

No que se refere à formação de competências necessárias aos profissionais da educação superior quanto à construção do saber ensinar, vai muito além da experiência profissional e dos conhecimentos da área de atuação. Nesse sentido, Perrenoud (2000) destaca que, na sociedade moderna, as tecnologias transformam, em uma velocidade cada vez maior, o trabalho e a vida cotidiana. Além disso, existe uma reorganização permanente do trabalho e forte competição empresarial devido à globalização, exigindo das organizações flexibilidade para a sobrevivência.

Nesse cenário espera-se que os profissionais se adaptem constantemente e desenvolvam novas competências ao longo da vida, principalmente as competências coletivas, como trabalho em equipe e novas formas de relacionamento com o aluno, entre outros. Porém, destaca o autor que não é apenas o mercado de trabalho que exige novas competências. Na sociedade hodierna, em todas as esferas da existência, surge a necessidade de novas competências e novos desempenhos em todas as áreas. Assim, 
para Perrenoud (2000), é normal a popularidade da noção das competências nas organizações, inclusive na profissão docente. Afinal, como destaca Masetto (2003), em uma economia globalizada e competitiva, o desenvolvimento das competências profissionais dos colaboradores é uma questão de sobrevivência empresarial.

Desde as últimas décadas do século anterior, entre críticas e apologias, o tema competências chegou ao cenário educacional juntamente com as questões relacionadas ao ensino e à aprendizagem no ensino superior, principalmente, com relação ao papel das instituições para com o mercado, ou seja, na sua função de preparar as competências necessárias ao mundo desenvolvido. Assim, passou a ocupar o centro da discussão nas organizações educacionais, nas reformas curriculares, nos atos legais, em nível global, como uma forma de articulação desses saberes - pedagógicos, científicos e da experiência - como capaz de possibilitar um novo modelo de gestão da sala de aula, de forma mais eficiente e eficaz.

Nesse sentido, como destaca Masetto (2003), a competência para ensinar não pode ser reduzida à promoção de conhecimento, apenas. O exercício da docência exige a mobilização de saberes da experiência, saberes pedagógicos e saberes científicos, como constitutivos da profissão docente, atualmente denominados como competências pessoais e profissionais - enquanto uma concepção pedagógica e profissional. Esses saberes são mobilizados para mediarem o processo de construção de identidade dos/as docentes, além das situações de ensino.

No entanto, ainda é possível inferir, a partir dos estudos realizados para este trabalho que, no âmbito da educação superior, este paradoxo ainda é uma realidade na maioria das instituições de ensino superior. A formação e a metodologia parecem ser negligenciadas pelos docentes dos cursos de bacharelado, cuja prática docente, de forma especial, se pauta nos saberes provenientes do exercício da profissão em outras instâncias profissionais. Por outro lado, não se pode desconsiderar a importância da experiência na constituição da identidade profissional do professor, como já analisado por Pimenta e Anastasiou (2005).

Segundo a pesquisadora, uma identidade profissional se constrói a partir da significação social da profissão e da revisão constante dos significados sociais da profissão. Práticas consagradas culturalmente permanecem significativas pelo significado que cada professor, como ator e autor, confere à atividade docente no seu cotidiano a partir de seus valores, seu modo de situar-se no mundo, sua história de vida, suas representações, seus saberes, anseios e angústias, suas relações com os pares, nas escolas, seus representantes sindicais, entre outros (Pimenta; Anastasiou, 2005). Portanto, é possível considerar, no âmbito da pedagogia universitária, a profissão docente e a formação para a profissão como um processo em transformação e reconstrução, que implica uma série de fatores, de ordem institucional, interna e externa à instituição e ao sujeito professor, no desenvolvimento de condições para análise e interpretação da sua própria atividade, que incorpora e ultrapassa o conhecimento emergente institucionalizado, como analisado por Pimenta e Anastasiou (2005). 


\section{A pedagogia universitária para Maria Isabel Cunha}

A expressão pedagogia universitária é definida na Enciclopédia de pedagogia universitária (2006) como um campo polissêmico de produção e aplicação dos conhecimentos pedagógicos na educação superior. Reconhece distintos campos científicos dos quais toma referentes epistemológicos pedagógicos e culturais para definir suas bases e características. No entanto, geralmente, não se exige formação pedagógica na docência do ensino superior porque, aparentemente, é suficiente o domínio de conhecimentos específicos, pois o que valoriza o docente universitário é a pesquisa e/ou o exercício profissional no campo. Como analisado por Cunha $(2004,2006)$, o curso superior é o único que não requer uma formação específica para o magistério.

Cunha (2004) entende a expressão pedagogia universitária como um campo polissêmico de produção e aplicação dos conhecimentos pedagógicos na educação superior que não se restringe à formação continuada. Reconhece distintos campos científicos dos saberes do âmbito do currículo e da prática pedagógica que incluem as formas de ensinar e de aprender. Incide sobre as teorias e as práticas de formação de professores e dos estudantes da educação superior; articula as dimensões do ensino e da pesquisa nos lugares e espaços de formação e pode envolver uma condição institucional, considerando-se como "pedagógico o conjunto de processos vividos no âmbito acadêmico" (Cunha, 2004, p. 321).

Como analisa Cunha (2008, p. 9), diferentemente dos outros graus de ensino, o professor do ensino universitário "se constituiu, historicamente, tendo como base a profissão paralela que exerce ou exercia no mundo do trabalho. A ideia de que quem sabe fazer sabe ensinar deu sustentação à lógica do recrutamento dos docentes", no entanto, "a universidade, pela sua condição de legitimadora do conhecimento profissional, tornou-se tributária de um poder arraigado nas macroestruturas sociais do campo do trabalho, dominadas, fundamentalmente, pelas corporações" (Cunha, 2008, p. 10). Citando Lucarelli $(2000$, p. 36$)$, a autora frisa que a pedagogia universitária é um "espaço de conexão de conhecimentos, subjetividades e cultura, exigindo um conteúdo científico, tecnológico ou artístico altamente especializado e orientado para a formação de uma profissão".

\section{A pedagogia universitária para Selma Garrido Pimenta e Lea das Graças} Anastasiou: do ensinar à ensinagem

Pimenta e Anastasiou (2005) põem em relação ao ensino e à aprendizagem, que tradicionalmente é denominado de Didática, um novo conceito denominado ensinagem, propondo uma nova referência na docência no ensino superior com significado de ensino eficaz, ou seja, somente será considerado como ensino se houver aprendizagem. No entender de Pimenta e Anastasiou (2005, p. 195), o conceito de "ensinagem é mais profundo que ensino", pois a ação de ensinar é definida na relação com a ação de aprender, ou seja, o ensino deve desencadear, necessariamente a ação de aprender. Assim, tanto o ensino e como a aprendizagem envolvem, necessariamente, uma ação, que deve gerar um resultado, que é a aprendizagem, sem a qual não se pode dizer que houve ensino. Para as autoras, o conceito de ensinagem comporta em si a superação da falsa e tradicional dicotomia entre ensinar e aprender. 
Nesse sentido, o ato de ensinar exige um novo processo de compreensão, pois, tradicionalmente, toma-se a simples transmissão da informação como ensino, ficando o professor como fonte de saber, tornando-se o portador e a garantia da verdade. No entanto, Pimenta e Anastasiou (2005, p. 205), questiona: "se o professor explica o conteúdo e o aluno não se apropriou dele, pode-se dizer que houve ensino?" No entendimento das autoras, "somente se poderia afirmar que houve ensino se, de fato, tivesse ocorrido a aprendizagem" (p. 205).

Diante do exposto, o sentido do termo ensinagem vai além da Didática, pois não basta ter a intencionalidade de ensinar. O conceito de ensinagem considera os objetivos que o docente estabelece e as habilidades a serem desenvolvidas em cada série de conteúdo; não se trata apenas de didática ou de ser didático ou não. Trata-se do resultado, atingir ou não os objetivos, portanto, há que ter clareza sobre onde se pretende chegar naquele momento com o processo de ensinagem.

$\mathrm{Na}$ ensinagem, a ação de ensinar é definida na relação com a ação de aprender, pois, para além da meta que revela a intencionalidade, o ensino desencadeia necessariamente a ação de aprender. A partir de pesquisas da prática em sala de aula e discussões sobre a docência universitária, essas autoras ressaltam a necessidade de estudos para compreender o funcionamento do ensino como fenômeno complexo, suas implicações estruturais e suas funções sociais no caso da docência em instituições de ensino superior. Segundo Pimenta e Anastasiou (2005), "o ensinar, enquanto atividade social tem como compromisso assegurar que todos aprendam. Neste sentido, a aprendizagem ao longo do processo de escolarização contribui para a humanização e, portanto, para a redução das desigualdades sociais" (p. 203).

Para Pimenta e Anastasiou (2005, p. 130), "ensino e aprendizagem constituem unidade dialética no processo, caracterizado pelo papel condutor do professor e pela auto atividade do aluno, em que o ensino existe para provocar a aprendizagem mediante tarefas contínuas do sujeito do processo". Portanto, o conceito de ensinagem pode ser relacionado ao "método dialético de ensinar" (p. 205), cuja perspectiva difere daqueles que se referem à aprendizagem como alcance de uma meta e implicam a intencionalidade de êxito. Assim, "atingir a meta definiria o êxito da tentativa e, somente, se poderia afirmar se houve ensino, se de fato tivesse ocorrido a aprendizagem" (p. 205). Com isso, as autoras frisam que não basta a intencionalidade para se dizer que houve ensino, é preciso considerar as evidências de aprendizagem, uma vez que, de acordo com o conceito de ensinagem, já tratado anteriormente, só se pode dizer que houve ensino, se houver aprendizagem.

\section{O professor universitário}

A atuação dos docentes do ensino superior tem incidência em toda a sociedade, pois o preparo de todos os tipos de profissionais que necessitam de formação especializada "está sob a sua responsabilidade", no entendimento de Pimenta e Anastasiou (2011, p. 7). No entanto, as autoras ressaltam que, para muitos professores, as teorias que fundamentam o universo da docência são desconhecidas e, por este motivo, elas concluem que não são, por esses docentes, utilizadas, pelo menos de forma consciente, em seus planejamentos de aula ou aplicadas em suas aulas. Muitos professores universitários se valem basicamente de três fontes para se constituírem 
professores, sendo estas: a experiência reproduzida oriunda da prática de sua profissão como especialista, a experiência adquirida enquanto aluno, e a experiência atual que vem sendo adquirida com a própria atuação como professora, no entendimento das autoras.

No entanto, para muitos professores, o território da docência é, do ponto de vista teórico, um universo um tanto desconhecido. O fazer em sala de aula se sustenta, em grande parte, num tripé fruto da combinação entre a reprodução do que realiza em sua atuação profissional específica; as experiências pregressas vividas enquanto aluno; e aquilo que sem sendo sedimentado por meio da sua própria atuação enquanto professor (Pimenta; Almeida, 2011).

Cunha (2006, p. 258) ainda sintetiza uma séria evidência desta forma: "a formação do professor universitário tem sido entendida, por força da tradição e ratificada pela legislação, como atinente quase que exclusivamente aos saberes do conteúdo de ensino". Essa ponderação ratifica a percepção sobre o quanto o professor universitário é desprovido de uma formação dirigida aos processos de ensino e aprendizado, ainda que este passe a ser o maior responsável por este processo a partir do momento em que inicia sua jornada de professor. Daí a importância de fazer uma reflexão mais rigorosa sobre as políticas de formação do professor universitário, pois no ensino superior isso se tornou uma tradição e, desta forma, afastou o campo da pedagogia da educação superior.

Atualmente, o cenário da educação superior continua sendo agravado pela falta de uma formação adequada ao ensino superior, quanto mais se compara esta situação, que é inclusive de abrangência mundial, com os crescentes impactos negativos na formação dos estudantes universitários e com a necessidade premente dos tempos atuais que exige renovação no contexto da sala de aula. Sobre isso Pimenta e Almeida (2011) afirmam que

o que se constata então é que o professor universitário não tem uma formação voltada para os processos de ensino e aprendizagem, pelos quais é responsável quando inicia sua vida acadêmica. Os elementos constitutivos de sua atuação docente, como relação da disciplina com o projeto do curso, planejamento, organização da aula, metodologias e estratégias didáticas, avaliação, peculiaridades da relação professor-aluno, Ihes são desconhecidos. Assim, predomina dentre os professores universitários brasileiros um despreparo e até um desconhecimento científico do que seja o processo de ensino e de aprendizagem, pelo qual serão responsáveis a partir do instante em que ingressam no departamento e na sala de aula. (p. 26)

Pelo exposto, é possível pontuar que o panorama internacional não é diferente, como aponta a literatura e, se considerados os problemas que esse desconhecimento acarreta na formação dos estudantes de graduação, é possível observar nos dois casos um crescimento da preocupação com a formação e o desenvolvimento profissional de professores universitários e com as inovações no campo da atuação didática. Referente a essa deficitária formação nos processos de ensino e aprendizagem do professor universitário, como argumentam as autoras, o contexto e os fatos parecem apontar para uma situação ainda mais difícil, a partir da necessidade crescente, oriunda das exigências atuais que cedem, cada vez, menos espaço para a execução de enfoques didáticos clássicos que são fortemente centrados na aula e na atuação do professor. 
Na visão de Pimenta e Almeida (2011), ao contrário, esse momento exige cada vez mais dos professores modos de ensino mais centrados em atividades a serem exercidas pelos alunos de forma autônoma, ou seja, "passamos por uma necessidade de quebra de paradigmas neste processo, o que naturalmente exige e exigirá ainda mais do professor universitário" (p. 28). Para tanto, as autoras defendem que há que se redesenhar novos planos de estudos, "o que requer novas capacidades dos docentes, de modo a favorecer o desenvolvimento de outras dimensões na formação dos alunos" (p. 28).

\section{Considerações finais}

Diante de novas demandas sociais e econômicas, as propostas de mudanças na educação são justificadas por questões que põem em discussão as finalidades e compromissos das instituições de ensino, historicamente definidos, enquanto instituições políticas e sociais, em todos os níveis. No caso da educação superior esses compromissos e finalidades são reestruturados e discutidos levando em consideração a sua relação com a sociedade em que está inserida e os desafios da sua realidade, sendo esta entendida neste trabalho como a realidade do mercado em face dos novos processos de produção no mundo globalizado e tecnologizado. É nesse cenário que surgem as discussões em torno da educação superior, ganhando destaque a chamada pedagogia universitária.

Nos últimos anos têm-se debruçado a debater questões do ensino superior e são unânimes em apontar a necessidade de haver uma pedagogia universitária. Também têm discutido a importância de se formar professores universitários pedagogicamente diante da complexidade do contexto do final do século 20 e início do século 21.

Considerando que a universidade é uma instituição educativa, enraizada nos contextos sociais, econômicos e culturais e que tem como finalidade o permanente exercício da produção de conhecimento e da formação de profissionais, esta pesquisa se insere na perspectiva da formação profissional sem, no entanto, desconsiderar o pilar em que se sustenta, legalmente, a universidade, a saber: ensino, pesquisa e extensão. A LDB estabelece em seu artigo 66 que "A preparação para o exercício do magistério superior far-se-á em nível de pós-graduação, prioritariamente em programas de mestrado e doutorado" (Brasil, 1995), mas não menciona mais orientações com relação à formação pedagógica. Diante deste princípio legal, os cursos de mestrado e doutorado são organizados muito mais com foco na pesquisa e, pouco é tratado de questões, propriamente, pedagógicas e metodológicas.

Diante do exposto e, tendo em vista esse tripé, a proposta de uma pedagogia para o ensino superior que contemple todas essas dimensões é um grande desafio, tanto para as instituições de ensino, quanto para os profissionais que atuam na docência, pois, a formação de profissionais exige considerar a grande diversificação de serviços e modos de produção, que ocorreram desde a década de 1970, em nível global, mas também de êxitos pelo direito à educação, traduzida na exigência da democratização do acesso à universidade, somando-se, ainda, os imperativos da economia, que passaram a exigir uma maior qualificação de mão de obra nos setores chave da indústria. 


\section{Referências}

CUNHA, Maria Isabel. Inovações pedagógicas e a reconfiguração de saberes no ensinar e no aprender na universidade. CONGRESSO LUSO-AFRO-BRASILEIRO DE CIÊNCIAS SOCIAIS, 8, 2004. Anais ... Coimbra: Universidade de Coimbra, 2004.

CUNHA, Maria Isabel. Pedagogia universitária. In: MOROSINI, Marília C. Enciclopédia de pedagogia universitária: glossário. Brasília: Inep, 2006, p. 349-405.

CUNHA, Maria Isabel. Os conceitos de espaço, lugar e território nos processos analíticos da formação dos docentes universitários. Educação Unisinos, v. 12, n. 3, 2008, p. 182186.

CUNHA, Maria Isabel. Inovações na educação superior: impactos na prática pedagógica e nos saberes da docência. Em Aberto, Brasília, v. 29, n. 97, 2016, p. 87-101.

GARCÍA, Carlos Marcelo. Formação de professores para a mudança educativa. Porto: Porto, 1999.

LEITE, Denise. Reformas universitárias, avaliação institucional participativa. Petrópolis: Vozes, 2005.

LEITE, Denise. Pedagogia universitária e inovação. In: CUNHA, Maria Isabel da (org.). Reflexões e práticas em pedagogia universitária. Campinas: Papirus, 2007, p. 11-26.

MASETTO, Marcos Tarciso (org.). Docência na universidade. Campinas: Papirus, 2006.

MASETTO, Marcos Tarciso. Competência pedagógica do professor universitário. São Paulo: Summus, 2003.

PIMENTA, Selma Garrido; ALMEIDA, Maria Isabel de (orgs.). Pedagogia universitária: caminhos para a formação de professores. São Paulo: Cortez, 2011.

PIMENTA, Selma Garrido; ANASTASIOU, Léa das Graças Camargos. Docência no ensino superior. São Paulo: Cortez, 2005.

TARDIF, Maurice. Saberes docentes e formação profissional. Petrópolis: Vozes, 2002.

Neide Pena Cária é doutora em Educação e professora na Universidade do Vale do Sapucaí.

Endereço: Rua Varese, 65/404 - condomínio Baronesa II, bloco 1 - 37555-102 Pouso Alegre - MG - Brasil.

E-mail: neideunivas@gmail.com.

Rogério Abranches da Silva é mestre em Educação, professor e coordenador do Núcleo de Empreendedorismo do Inatel.

Endereço: Avenida Vereador João Batista da Costa, 261 - 37540-000 - Santa Rita do Sapucaí - MG - Brasil.

E-mail: rogeriosilva@inatel.br.

Recebido em 23 de novembro de 2017.

Aceito em 6 de abril de 2018. 